\title{
Studi Implementasi Komunikasi Data Menggunakan Power Line Communication di Kampus ITTP
}

\author{
Gunawan Wibisono ${ }^{1}$, Muhammad Helmi Sukoco ${ }^{2}$, Kukuh Nugroho ${ }^{3}$ \\ ${ }^{1}$ Prodi S1 Teknik Elektro Institut Teknologi Telkom Purwokerto, Jl DI Panjaitan 128 Purwokerto 53147 Indonesia \\ 2,3 Prodi S1 Teknik Telekomunikasi Institut Teknologi Telkom Purwokerto, J1 DI Panjaitan 128 Purwokerto 53147 Indonesia \\ Email : ${ }^{1}$ wibisono@ittelkom-pwt.ac.id, ${ }^{2}$ helmimuhammad224@gmail.com, ${ }^{3}$ kukuh@ittelkom-pwt.ac.id
}

\begin{abstract}
Abstrak- Kabel listrik berfungsi untuk menyalurkan energi listrik ke peralatan listrik yang sering digunakan di kehidupan sehari - hari. Selain itu, kabel listrik juga dapat dimanfaatkan sebagai piranti komunikasi data antar perangkat seperti komputer, handphone dan perangkat mobile lainnya. Teknologi ini disebut dengan Power Line Communication (PLC). Dalam penelitian ini dilakukan implementasi sistem PLC dalam membangun sebuah jaringan menggunakan media kabel listrik untuk menghubungkan beberapa perangkat jaringan tanpa memerlukan instalasi baru karena jalur yang digunakan sudah terdistribusi di setiap tempat menggunakan perangkat powerline, serta menggunakan perangkat jaringan yang terhubung secara wireless ke perangkat mobile pada jaringan wireless LAN (WLAN). Sistem PLC diterapkan pada tiga kali Pengujian, diantaranya membandingkan sistem PLC dengan tanpa sistem PLC, diterapkan berdasarkan jarak serta berdasarkan beban listrik yang diterapkan. Tiga Pengujian yang dilakukan dilihat berdasarkan parameter Quality of Service (QoS) seperti throughput, delay, jitter dan packet loss. Pada pengujian antara sistem PLC menghasilkan kinerja QoS lebih baik dibandingkan tanpa PLC, kemudian untuk pengujian bedasarkan jarak menghasilkan QoS yang baik walaupun cenderung konstan serta pengujian berdasarkan beban listrik menghasilkan QoS yang baik meskipun cenderung konstan.
\end{abstract}

Kata Kunci- Power Line Communication, Electric Cable, Quality of Service

\section{PENDAHULUAN}

Di era informasi, komunikasi data merupakan bagian integral yang sangat penting dalam pertukaran data atau informasi. Komunikasi data sendiri merupakan kumpulan beberapa teknologi jaringan, komputer, telekomunikasi [1]. Agar komunikasi data dapat dilakukan dibutuhkan sebuah media seperti kabel ethernet, serat optik, maupun gelombang radio. Selain media tersebut, ada beberpa media alternatif yang bisa digunakan dalam suatu jaringan [2], misalnya kabel listrik. Kabel listrik yang digunakan pada suatu jaringan komputer biasa disebut dengan Power Line Communication (PLC) [3]. PLC adalah teknologi yang memanfaatkan media transmisi berupa jalur - jalur listrik, dimana dapat menghubungkan perangkat elektronik seperti, PC, laptop dan perangkat lainnya [3], [4]. Penggunaan sistem PLC ini bertujuan agar pemanfaatan kabel listrik menjadi lebih maksimal yang tidak hanya digunakan sebagai penghantar listrik saja. Instalasi juga lebih mudah karena tidak perlu melakukan penarikan kabel khusus untuk jaringan.

Implementasi sistem PLC diterapkan pada jaringan Wireless LAN (WLAN) atau biasa disebut dengan Wi-Fi yang merupakan jaringan Local Area Network (LAN) yang menghubungkan beberapa perangkat seperti komputer, laptop dan perangkat mobile lainnya menggunakan gelombang radio [5]. Sedangkan Quality of Service (QoS) adalah parameter yang digunakan untuk mengukur kinerja pada suatu jaringan yang dibuat [6]. Parameter-parameter QoS diantaranya throughput, delay, jitter dan packet loss [7].

Berdasarkan Penelitian Galuh Lukitasari, Aad Haryadi dan Ridho Hendra Yoga Perdana (2018) melakukan implementasi powerline communication untuk monitoring Penggunaan arus di Politeknik Negeri Malang dengan menggunakan 2 perangkat yang berfungsi sebagai transmitter dan receiver. Dimana perangkat transmitter terdiri dari modul KQ330 yang merupakan modem PLC, mikrokontroller, dan sensor arus SCT-013 yang mendeteksi arus fasa R, S, dan T. Sedangkan pada perangkat receiver terdiri dari modul KQ330, mikrokontroller, server dan user [1]. Hasil penelitiannya menunjukkan bahwa Penggunaan sensor arus SCT-013 dapat memonitoring Penggunaan arus dengan keakuratan yang hampir mendekati 100\%. Penggunaan modul KQ330 sebagai modem PLC dapat mengirimkan data dari client ke server dengan nilai BER yang sangat kecil dengan syarat jarak client dan server tidak terlalu jauh dari server. Penerapan sistem PLC untuk monitoring Penggunaan arus di Politeknik Negeri Malang di setiap kelas dan di Gedung dapat diketahui dan data arusnya tercatat dan disimpan di database. Perbedaan dengan penelitian yang dilakukan ada pada salah satu Pengujian dibuat jarak yang digunakan kurang lebih $36 \mathrm{~m}$ dengan percobaan yang dilakukan yaitu download file, upload file dan streaming video. Serta pada masing-masing perangkat powerline untuk transmitter dan receiver menggunakan chipset QCA7420 dengan kecepatan data mencapai 500 Mbps.

Penelitian Agus Rochadi (2016) yang berjudul "Penggunaan Homeplug AV Powerline Adapter" yang menggunakan jaringan listrik di politeknik negeri semarang, yang meneliti Penggunaan perangkat homeplug powerline menggunakan parameter QoS (Quality of Service) yaitu throughput, packet loss, delay, dan jitter [2]. Hasil penelitiannya menunjukkan bahwa Penggunaan homeplug powerline dapat dimanfaatkan untuk Komunikasi antar komputer dengan berupa layanan download dan upload. Berdasarkan kinerja powerline saat download file pada throughput Ketika jarak powerline dan beban klien semakin bertambah maka nilai throughput semakin kecil. Nilai throughput terbesar pada jarak $21.05 \mathrm{~m}$ (70,224 Mbps) dan jarak $79.23 \mathrm{~m}(5,445 \mathrm{Mbps})$. Pada delay Ketika jarak powerline dan beban klien semakin bertambah maka nilai delay semakin besar. Nilai delay terbesar ada pada jarak 79.23 $\mathrm{m}$ dengan beban $3 \mathrm{klien}(1,643 \mathrm{~ms})$ dan delay terkecil ada pada jarak $21.05 \mathrm{~m}$ dengan beban 1 klien $(0,122 \mathrm{~ms})$. Untuk jitter juga mengalami hal yang sama dengan kondisi sebelumnya dimana nilai jitter terkecil pada ukuran file 189 MB 1 klien pada jarak $21.05 \mathrm{~m}(0,185 \mathrm{~ms})$ dan nilai jitter terbesar pada ukuran file $27 \mathrm{MB} 3$ klien pada jarak $79.23 \mathrm{~m}$ $(2,728 \mathrm{~ms})$. Berdasarkan kinerja powerline saat upload file 
pada throughput Ketika jarak powerline dan beban klien bertambah maka nilai throughput semakin kecil. Dimana untuk nilai throughput terbesar dengan file $189 \mathrm{MB}$ pada jarak $21.05 \mathrm{~m}(53,248 \mathrm{Mbps})$ dan throughput terkecil pada jarak $33.45 \mathrm{~m}$ (2,612 Mbps). Pada delay Ketika jarak powerline dan beban klien bertambah nilai delay semakin besar. Dimana untuk nilai delay terbesar pada jarak $33.45 \mathrm{~m}$ dengan beban 3 klien menggunakan file $189 \mathrm{MB}(2,829 \mathrm{~ms})$, sedangkan untuk nilai delay terkecil ada pada jarak $21.05 \mathrm{~m}$ dengan beban 1 klien menggunakan file $189 \mathrm{MB}(0,150 \mathrm{~ms})$. Untuk nilai jitter yang terkecil terletak pada jarak $21.05 \mathrm{~m}$ dengan ukuran file $189 \mathrm{MB}$ beban 1 klien $(0,260 \mathrm{~ms})$, sedangkan nilai jitter terbesar ada pada jarak 33,45 m dengan ukuran file $27 \mathrm{MB}$ beban 3 klien $(5,327 \mathrm{~ms})$. Berdasarkan pengelompokan delay, jitter dan packet loss dari standar TIPHON termasuk dalam kategori sangat bagus dan jaringan powerline sangat layak dimanfaatkan untuk Komunikasi data. Yang membedakan dengan penelitian ini ada pada Pengujian yang dilakukan, dimana terdapat 3 kali Pengujian yang dilakukan serta perangkat yang digunakan ada 2 jenis yaitu versi PWR-Line adapter dan PWR-Line Access Point.

Pada penelitian Faris, Suhendar dan Anggoro Suryo Pramudyo (2014) melakukan penerapan powerline communication pada sistem monitoring, controlling peralatan listrik dan sharing file antar computer menggunakan perangkat master dan slave yang meliputi komponen modem PLC LM1893N, switch mode, mikrokontroller atmega128, interface RS232, LCD, power supply, sensor cahaya dan driver lampu. Sedangkan untuk perangkat lunak dibuat menggunakan software MS Visual Basic dan software code vision [3]. Hasil penelitiannya menunjukkan bahwa peralatan yang dirancang untuk diterapkan pada jaringan listrik berfungsi dengan baik untuk controlling, monitoring dan sharing file antar komputer. Komponen IC LM1893N yang digunakan sebagai modem PLC dapat bekerja sesuai dengan spesifikasi yang ditunjukkan oleh datasheet. Pengujian yang dilakukan mampu mengirimkan data dengan baik yang difungsikan sebagai alamat untuk controlling dan monitoring maupun sharing file dengan kecepatan 1200 bps dan jarak sampai dengan kurang dari $200 \mathrm{~m}$ dengan error $0 \%$. Yang membedakan dengan penelitian yang dilakukan ada pada percobaan yang dilakukan pada setiap Pengujian, diantaranya download file, upload file dan streaming video. Serta pada chipset yang digunakan pada perangkat powerline menggunakan IC QCA7420 pada kedua perangkat powerline adapter dan powerline accesspoint dengan kecepatan data rate mencapai $500 \mathrm{Mbps}$ [8].

Sedangkan penelitian Mukesh Kumar Varma, Zainal Abdin Jaffery dan Ibraheem (2019) melakukan analisis pemodelan kanal dan noise pada sistem Broadband Powerline Communication (BPLC) menggunakan perumusan matematika. Diusulkannya sistem BPLC dilakukan untuk mengurangi perfomansi error dan meningkatkan kinerja fungsi pengiriman kanal dengan mengevaluasinya menggunakan modulasi digital yang hasilnya mengacu pada Bit Error Rate (BER) dan Signal Noise to Ratio (SNR) [4]. Hasil penelitiannya bahwa sistem BPLC dapat digunakan untuk
Komunikasi data dengan kecepatan tinggi, dimana Penggunaan saluran dan noise pada kanal sangat terbatas, Pengujian tersebut dapat disimulasikan menggunakan software Matlab.

\section{BAHAN DAN METODE}

Bagian ini menjelaskan perancangan topologi jaringan, serta konfigurasi perangkat powerline dan perangkat jaringan.

\section{A. Perancangan Topologi Jaringan}

Topologi jaringan yang dirancang meliputi beberapa hal, seperti media transmisi yang digunakan dan perangkat yang digunakan. Pada gambar 1 untuk topologi jaringan dengan sistem PLC menggunakan perangkat jaringan seperti routerboard, perangkat client seperti laptop, perangkat powerline seperti PWR-Line adapter yang digunakan untuk menghubungkan antar perangkat jaringan melalui kabel listrik sebagai media transmisinya dan PWR-Line access point yang fungsinya sama dengan PWR-Line adapter namun dapat bertindak sebagai access point.

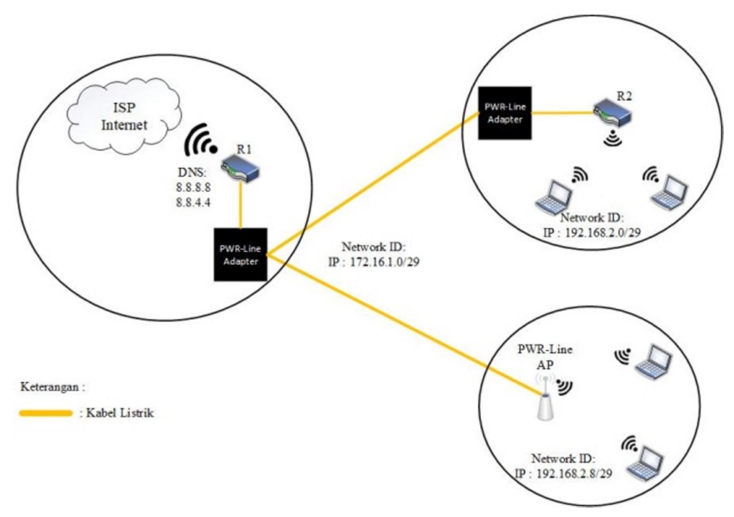

Gbr. 1 Topologi Jaringan WLAN dengan sistem PLC

Sedangkan topologi jaringan tanpa sistem PLC ditunjukkan pada gambar 2 .

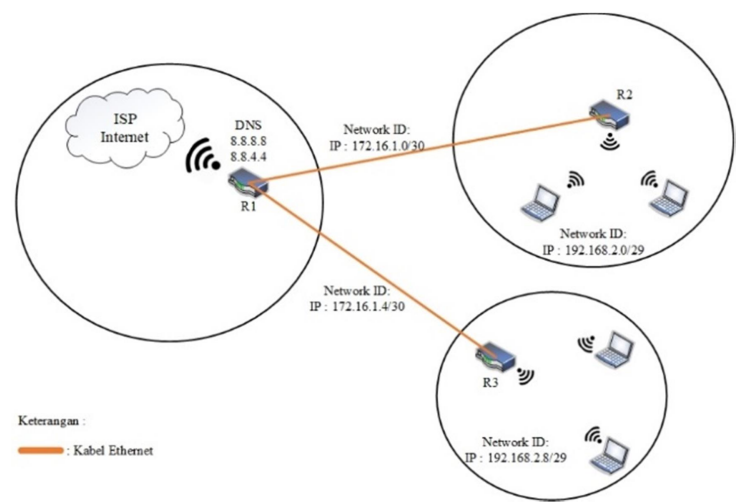

Gbr. 2 Topologi Jaringan WLAN tanpa sistem PLC 


\section{B. Konfigurasi Perangkat Powerline dan Perangkat Jaringan}

Topologi jaringan menggunakan sistem PLC menggunakan perangkat jaringan seperti perangkat routerboard, beberapa perangkat client seperti laptop, perangkat powerline seperti PWR-Line adapter yang berfungsi menghubungkan antar perangkat jaringan melalui kabel listrik sebagai media transmisinya dan PWR-Line access point dengan fungsi yang sama dengan PWR-Line adapter namun dapat menyediakan layanan Wi-Fi. Konfigurasi yang dilakukan di setiap perangkat jaringan meliputi beberapa macam diantaranya IP Address, Dynamic Host Control Protocol (DHCP Server \& DHCP Client), Domain Name Server (DNS), Wireless, Firewall dan Hotspot [9].

\section{Pengambilan Data}

Proses pengambilan data dilakukan berdasarkan parameter QoS yand diterapkan, hal ini dilakukan untuk mengetahui seberapa handal kinerja yang dilakukan pada aplikasi yang dijalankan pada suatu jaringan. Parameter-parameter yang diuji antara lain, throughput, packet loss, delay, dan jitter.

Sedangkan variabel-variabel yang digunakan antara lain adalah jarak dan beban listrik.

\section{HASIL DAN PEMBAHASAN}

Pengujian dilakukan sebanyak 3 kali, dimana pengujian pertama membandingkan antara kinerja topologi jaringan menggunakan sistem PLC dengan tanpa sistem PLC. Kemudian pengujian kedua menerapkan sistem PLC pada topologi jaringan berdasarkan jarak yang diterapkan. Serta pengujian ketiga menerapkan sistem PLC pada topologi jaringan berdasarkan beban listrik yang digunakan. Setiap pengujian yang dilakukan memiliki empat buah client yang masing-masing melakukan tiga kali percobaan diantaranya download, upload dan streaming video. Data - data yang didapatkan kemudian direkapitulasi menggunakan aplikasi wireshark dan dilakukan perhitungan yang sesuai berdasarkan parameter QoS.

\section{A. Perbandingan Topologi Jaringan}

Pengujian dilakukan dengan membandingkan dua topologi jaringan yaitu dengan menggunakan sistem PLC dan tanpa sistem PLC yang hanya menggunakan media transmisi kabel ethernet. Dengan melakukan 3 kali percobaan yaitu download, upload dan streaming video.

TABEL I

NILAI RATA-RATA THROUGHPUT PADA KEDUA TOPOLOGI JARINGAN

\begin{tabular}{|c|c|c|}
\hline \multirow{2}{*}{ Kategori } & \multicolumn{2}{|c|}{ Media Transmisi } \\
\cline { 2 - 3 } & Tanpa Sistem PLC & Sistem PLC \\
\hline Download & $11070 \mathrm{Kbps}$ & $18291.5 \mathrm{Kbps}$ \\
\hline Upload & $2851.5 \mathrm{Kbps}$ & $7300 \mathrm{Kbps}$ \\
\hline Streaming Video & $1602 \mathrm{Kbps}$ & $1382.5 \mathrm{Kbps}$ \\
\hline
\end{tabular}

Hasil dari rata - rata nilai throughput yang didapatkan dapat diamati pada tabel 1 . Untuk percobaan download dan upload throughput yang dihasilkan cenderung meningkat pada topologi jaringan sistem PLC. Sedangkan percobaan streaming video throughput yang dihasilkan juga cenderung menurun pada topologi jaringan sistem PLC. Hal ini dikarenakan data yang dilewatkan pada kabel listrik lebih cepat meski dilakukan pada saat kondisi peralatan listrik digunakan semua. Walaupun data yang dilewatkan ditumpangkan pada Sinyal carrier namun tidak menutup kemungkinan bahwa data yang dilewatkan lebih besar dibandingkan tanpa sistem PLC. Serta antara kedua topologi jaringan antara tanpa menggunakan sistem PLC dengan topologi jaringan menggunakan sistem PLC memberikan nilai throughput dengan kategori baik sekali, namun diantaranya keduanya sistem PLC menghasilkan nilai throughput lebih baik pada pengujian download dan upload sedangkan untuk streaming video topologi jaringan tanpa sistem PLC masih memberikan nilai lebih baik dibandingkan dengan sistem PLC.

TABEL III

NILAI RATA-RATA PACKET LOSS PADA KEDUA TOPOLOGI JARINGAN

\begin{tabular}{|c|c|c|}
\hline \multirow{2}{*}{ Kategori } & \multicolumn{2}{|c|}{ Media Transmisi } \\
\cline { 2 - 3 } & Tanpa Sistem PLC & Sistem PLC \\
\hline Download & $8.9 \%$ & $8.1 \%$ \\
\hline Upload & $0.075 \%$ & $0.025 \%$ \\
\hline Streaming Video & $8.675 \%$ & $9.175 \%$ \\
\hline
\end{tabular}

Hasil dari rata - rata nilai packet loss yang didapatkan dapat diamati pada tabel 2. Untuk ketiga percobaan yang dilakukan packet loss yang dihasilkan cenderung menurun pada percobaan download dan upload sedangkan percobaan streaming video cenderung meningkat di setiap topologi jaringan. Hal tersebut tidak lepas dari pengambilan data yang dimana dilakukan secara tidak bersamaan, namun bukan berarti packet loss yang dihasilkan semakin membaik ataupun memburuk. Kemudian jika dilihat dari segi rentang packet loss yang didapat untuk percobaan download dan streaming video masuk kategori baik sedangkan pada percobaan upload masuk kategori baik sekali. Hal tersebut dikarenakan penggunaan beban terhadap peralatan listrik yang digunakan seiring pengambilan data yang dilakukan. Akan tetapi dampak yang terlihat hanya percobaan download dan streaming video sedangkan pada percobaan upload tidak terlalu berdampak.

TABEL IIIII

NILAI RATA-RATA DELAY PADA KEDUA TOPOLOGI JARINGAN

\begin{tabular}{|c|c|c|}
\hline \multirow{2}{*}{ Kategori } & \multicolumn{2}{|c|}{ Media Transmisi } \\
\cline { 2 - 3 } & Tanpa Sistem PLC & Sistem PLC \\
\hline Download & $0.769428 \mu \mathrm{s}$ & $0.44722 \mu \mathrm{s}$ \\
\hline Upload & $3.234231 \mu \mathrm{s}$ & $1.501177 \mu \mathrm{s}$ \\
\hline Streaming Video & $4.375051 \mu \mathrm{s}$ & $5.390418 \mu \mathrm{s}$ \\
\hline
\end{tabular}

Hasil dari rata - rata nilai delay yang didapatkan dapat diamati pada tabel 3. Untuk pengujian menggunakan sistem PLC seperti percobaan download dan upload delay yang dihasilkan cenderung menurun sedangkan percobaan streaming video cenderung meningkat pada pengujian tanpa sistem PLC. Hal tersebut terjadi dikarenakan adanya penurunan waktu pengecekan untuk setiap paket yang 
dikirimkan pada percobaan download dan upload sedangkan percobaan streaming video mengalami peningkatan pada saat pengecekan untuk setiap paket yang datang. Selain itu delay yang didapatkan pada kedua topologi jaringan masing-masing dikarenakan adanya pengaruh penggunaan beban peralatan listrik yang digunakan pada saat penelitian yang dilakukan. Meskipun pada 3 percobaan yang dilakukan masuk ke kategori baik sekali karena delay yang dihasilkan kurang dari atau $<150 \mathrm{~ms}$. Namun untuk parameter delay beban listrik yang digunakan memiliki dampak yang cukup berpengaruh di 3 percobaan yang dilakukan.

TABEL IVV

NILAI RATA-RATA JITTER PADA KEDUA TOPOLOGI JARINGAN

\begin{tabular}{|c|c|c|}
\hline \multirow{2}{*}{ Kategori } & \multicolumn{2}{|c|}{ Media Transmisi } \\
\cline { 2 - 3 } & Tanpa Sistem PLC & Sistem PLC \\
\hline Download & $1.391027 \mu \mathrm{s}$ & $0.762271 \mu \mathrm{s}$ \\
\hline Upload & $6.139981 \mu \mathrm{s}$ & $2.883023 \mu \mathrm{s}$ \\
\hline Streaming Video & $7.890246 \mu \mathrm{s}$ & $9.468469 \mu \mathrm{s}$ \\
\hline
\end{tabular}

Hasil dari rata - rata nilai jitter yang didapatkan dapat diamati pada tabel 4.. Jitter yang dihasilkan cenderung menurun pada percobaan download dan upload pada topologi jaringan sistem PLC jitter pada streaming video yang dihasilkan cenderung meningkat pada topologi jaringan tanpa sistem PLC. Hal ini menandakan bahwa delay pada setiap paket yang dikirimkan bervariasi pada kedua topologi jaringan yang diujikan. Selain itu jitter yang didapat pada kedua topologi jaringan masing-masing dipengaruhi oleh penggunaan beban peralatan listrik yang digunakan pada saat penelitian yang dilakukan. Nilai jitter yang didapatkan 3 percobaan yang dilakukan masuk ke kategori baik sekali, namun jika dibandingkan untuk percobaan download dan upload pada topologi jaringan dengan sistem PLC lebih baik daripada tanpa sistem PLC sedangkan untuk percobaan streaming video pada topologi jaringan tanpa sistem PLC lebih baik

\section{B. Perfomansi Jaringan Berdasarkan Jarak}

Pengujian dilakukan dengan menerapkan sistem PLC pada topologi jaringan berdasarkan jarak antar perangkat power line. Jarak yang diterapkan antara lain $8 \mathrm{~m}, 9 \mathrm{~m}, 27 \mathrm{~m}$ dan $36 \mathrm{~m}$.

TABEL V

NILAI RATA-RATA THROUGHPUT (KBPS)

\begin{tabular}{|c|c|c|c|c|}
\hline \multirow{2}{*}{ Kategori } & \multicolumn{4}{|c|}{ Jarak } \\
\cline { 2 - 5 } & $\mathbf{8 m}$ & $\mathbf{9 m}$ & $\mathbf{2 7 m}$ & $\mathbf{3 6 m}$ \\
\hline Download & 18291.5 & 13067.75 & 15448 & 12578.375 \\
\hline Upload & 7300 & 4676.75 & 6783.125 & 3617.375 \\
\hline Streaming Video & 1382.5 & 1316.25 & 3266.875 & 1330.875 \\
\hline
\end{tabular}

Hasil dari rata - rata nilai throughput yang didapatkan dapat diamati pada tabel 5. Untuk setiap jarak yang diterapkan pada percobaan menghasilkan throughput yang konstan. Meskipun jarak yang diterapkan semakin besar namun nilai yang dihasilkan pada setiap percobaan seperti download, upload dan streaming video tetap konstan. Selain itu adanya peralatan listrik yang digunakan di setiap jarak yang digunakan tidak terlalu berdampak pada penyebaran data di semua perangkat jaringan yang digunakan. Namun pada percobaan download, upload dan streaming video menghasilkan nilai throughput dengan kategori baik sekali

TABEL VI

NiLAI RATA-RATA PACKET LOSS

\begin{tabular}{|c|c|c|c|c|}
\hline \multirow{2}{*}{ Kategori } & \multicolumn{4}{|c|}{ Jarak } \\
\cline { 2 - 5 } & $\mathbf{8 m}$ & $\mathbf{9 m}$ & $\mathbf{2 7 m}$ & $\mathbf{3 6 m}$ \\
\hline Download & $8.1 \%$ & $8.3625 \%$ & $7.85 \%$ & $7.6125 \%$ \\
\hline Upload & $0.025 \%$ & $0.025 \%$ & $0.8875 \%$ & $0.1625 \%$ \\
\hline Streaming Video & $9.175 \%$ & $8.5375 \%$ & $8.625 \%$ & $7.8625 \%$ \\
\hline
\end{tabular}

Hasil dari rata - rata nilai packet loss yang didapatkan dapat diamati pada tabel 6. Untuk setiap jarak yang diterapkan pada percobaan menghasilkan packet loss yang konstan di setiap percobaan yang dilakukan. Meskipun adanya penambahan jarak serta penggunaan peralatan listrik, namun hal tersebut tidak memberikan dampak pada nilai packet loss yang dihasilkan. Selain itu nilai packet loss yang dihasilkan juga termasuk ke beberapa kategori yang berbeda, seperti pada percobaan download dan streaming video masuk ke kategori baik sedangkan pada percobaan upload masuk ke kategori baik sekali.

TABEL VII

NILAI RATA-RATA DELAY $(\mu S)$

\begin{tabular}{|c|c|c|c|c|}
\hline \multirow{2}{*}{ Kategori } & \multicolumn{4}{|c|}{ Jarak } \\
\cline { 2 - 5 } & $\mathbf{8 m}$ & $\mathbf{9 m}$ & $\mathbf{2 7 m}$ & $\mathbf{3 6 m}$ \\
\hline Download & 0.44722 & 2.007433 & 0.47718 & 0.547089 \\
\hline Upload & 1.501177 & 2.216008 & 2.302778 & 2.644887 \\
\hline Streaming Video & 5.390418 & 5.574233 & 3.991379 & 5.726059 \\
\hline
\end{tabular}

Hasil dari rata - rata nilai delay yang didapatkan dapat diamati pada tabel 7. Untuk setiap jarak yang diterapkan pada percobaan download dan streaming video nilai delay yang dihasilkan cenderung konstan meskipun jaraknya semakin besar. Namun untuk percobaan upload Ketika jarak semakin besar delay yang diperoleh semakin besar. Hal tersebut dikarenakan adanya pengaruh dari penggunaan peralatan listrik yang memberikan dampak yang cukup terlihat pada delay yang dihasilkan untuk percobaan upload. Namun hal ini tidak memberikan dampak yang besar pada percobaan download dan streaming video pada saat peralatan listrik digunakan. Sehingga penyebaran data yang dilakukan tidak terlalu berdampak meskipun dari ketiga pengujian yang dilakukan mendapatkan delay dengan kategori baik sekali.

TABEL VIII

NiLAI RATA-RATA JITTER $(\mu \mathrm{S})$

\begin{tabular}{|c|c|c|c|c|}
\hline \multirow{2}{*}{ Kategori } & \multicolumn{4}{|c|}{ Jarak } \\
\cline { 2 - 5 } & $\mathbf{8 m}$ & $\mathbf{9 m}$ & $\mathbf{2 7 m}$ & $\mathbf{3 6 m}$ \\
\hline Download & 0.762271 & 3.670734 & 0.852312 & 0.96156 \\
\hline Upload & 2.883023 & 4.14688 & 4.332334 & 4.51766 \\
\hline Streaming Video & 9.468469 & 9.662027 & 7.022951 & 9.937966 \\
\hline
\end{tabular}

Hasil dari rata - rata nilai jitter yang didapatkan dapat diamati pada tabel 8. Untuk setiap jarak yang diterapkan pada percobaan download dan streaming video jitter yang 
dihasilkan cenderung konstan meskipun jaraknya semakin besar. Namun pada percobaan upload Ketika jarak semakin besar jitter yang diperoleh semakin besar. Hal ini juga terjadi pada pengujian dengan parameter delay yang dimana grafik yang dihasilkan ketiga percobaan yang dilakukan berbanding lurus antara parameter delay dan jitter. Penggunaan peralatan listrik memberikan hanya berdampak pada percobaan upload saja sedangkan pada percobaan download dan streaming video tidak terlalu berdampak. Namun dari ketiga pengujian yang dilakukan menghasilkan nilai jitter dengan kategori baik sekali.

\section{Perfomansi Jaringan Berdasarkan Beban Listrik}

Pengujian dilakukan dengan menerapkan sistem PLC pada topologi jaringan berdasarkan beban listrik yang digunakan, diantaranya beban listrik rendah, beban listrik sedang dan beban listrik tinggi.

TABEL IX

NILAI RATA-RATA THROUGHPUT (KBPS)

\begin{tabular}{|c|c|c|c|}
\hline \multirow{2}{*}{ Kategori } & \multicolumn{3}{|c|}{ Beban Listrik } \\
\cline { 2 - 4 } & Rendah & Sedang & Tinggi \\
\hline Download & 4099.25 & 6631.25 & 11632.25 \\
\hline Upload & 2063.5 & 2008.5 & 9289 \\
\hline Streaming Video & 1175 & 1395 & 980 \\
\hline
\end{tabular}

Hasil dari rata - rata nilai throughput yang didapatkan dapat diamati pada tabel 9. Untuk setiap beban listrik yang diterapkan pada percobaan download untuk setiap beban listrik yang diterapkan mulai dari rendah, sedang dan tinggi mengalami peningkatan pada throughput yang dihasilkan sedangkan untuk percobaan upload dan streaming video cenderung konstan meskipun penggunaan beban listrik terus bertambah. Dimana beban listrik yang digunakan cukup memberikan dampak yang besar pada percobaan download sehingga throughput dihasilkan semakin besar. Selain itu nilai-nilai throughput yang didapatkan masuk ke kategori lumayan yang berada untuk percobaan streaming video serta baik sekali untuk kedua percobaan yaitu download dan upload.

TABEL X

NILAI RATA-RATA PACKET LOSS

\begin{tabular}{|c|c|c|c|}
\hline \multirow{2}{*}{ Kategori } & \multicolumn{3}{|c|}{ Beban Listrik } \\
\cline { 2 - 4 } & Rendah & Sedang & Tinggi \\
\hline Download & $8.325 \%$ & $9.075 \%$ & $9.8325 \%$ \\
\hline Upload & $0.05 \%$ & $0.075 \%$ & $0 \%$ \\
\hline Streaming Video & $9.675 \%$ & $9.725 \%$ & $9.2 \%$ \\
\hline
\end{tabular}

Hasil dari rata - rata nilai packet loss yang didapatkan dapat diamati pada tabel 10. Untuk setiap beban listrik yang diterapkan pada percobaan download untuk setiap beban listrik yang diterapkan mulai dari rendah, sedang dan tinggi mengalami peningkatan pada packet loss yang didapatkan. Sedangkan pada percobaan upload dan streaming video untuk packet loss yang dihasilkan pada setiap kondisi beban listrik cenderung konstan. Meskipun Penggunaan peralatan listrik yang semakin bertambah pada setiap percobaan yang dilakukan namun hanya percobaan download yang lebih berdampak dibandingkan dengan percobaan upload dan streaming video. Untuk nilai-nilai packet loss yang dihasilkan pada setiap percobaan yang dilakukan seperti download dan streaming video masuk ke kategori baik sedangkan untuk percobaan upload masuk ke kategori baik sekali.

TABEL XI

NILAI RATA-RATA DELAY

\begin{tabular}{|c|c|c|c|}
\hline \multirow{2}{*}{ Kategori } & \multicolumn{3}{|c|}{ Beban Listrik } \\
\cline { 2 - 4 } & Rendah & Sedang & Tinggi \\
\hline Download & $1.834074 \mu \mathrm{s}$ & $1.17227 \mu \mathrm{s}$ & $0.671015 \mu \mathrm{s}$ \\
\hline Upload & $4.587892 \mu \mathrm{s}$ & $6.119298 \mu \mathrm{s}$ & $1.204696 \mu \mathrm{s}$ \\
\hline Streaming Video & $6.147421 \mu \mathrm{s}$ & $6.78789 \mu \mathrm{s}$ & $6.703738 \mu \mathrm{s}$ \\
\hline
\end{tabular}

Hasil dari rata - rata nilai delay yang didapatkan dapat diamati pada tabel 11. Untuk setiap beban listrik yang diterapkan pada percobaan download mengalami penurunan pada delay di setiap kondisi beban listrik yang diterapkan. Sedangkan pada percobaan upload dan streaming video cenderung konstan pada delay yang dihasilkan. Walaupun semakin bertambah peralatan listrik yang digunakan di setiap kondisi beban listrik namun hanya berdampak di percobaan download saja akan tetapi pada percobaan upload dan streaming video tidak terlalu berdampak. Untuk nilai-nilai delay yang dihasilkan pada setiap percobaan yang dilakukan di setiap kondisi yang diterapkan masuk ke kategori baik sekali

TABEL XII

NILAI RATA-RATA JITTER

\begin{tabular}{|c|c|c|c|}
\hline \multirow{2}{*}{ Kategori } & \multicolumn{3}{|c|}{ Beban Listrik } \\
\cline { 2 - 4 } & Rendah & Sedang & Tinggi \\
\hline Download & $3.401876 \mu \mathrm{s}$ & $1.982169 \mu \mathrm{s}$ & $1.231392 \mu \mathrm{s}$ \\
\hline Upload & $8.735934 \mu \mathrm{s}$ & $11.626606 \mu \mathrm{s}$ & $2.339757 \mu \mathrm{s}$ \\
\hline Streaming Video & $10.54683 \mu \mathrm{s}$ & $11.895382 \mu \mathrm{s}$ & $11.959162 \mu \mathrm{s}$ \\
\hline
\end{tabular}

Hasil dari rata - rata nilai jitter yang didapatkan dapat diamati pada tabel 12. Untuk setiap beban listrik yang diterapkan pada percobaan download di setiap kondisi beban listrik yang diterapkan mengalami penurunan terhadap jitter yang dihasilkan. Berikutnya pada percobaan upload di setiap kondisi beban listrik yang diterapkan jitter yang didapatkan cenderung konstan. Serta pada percobaan streaming video jitter yang diperoleh mengalami peningkatan. Sehingga untuk parameter jitter di Pengujian berdasarkan beban listrik tidak berbanding lurus dengan parameter delay di Pengujian berdasarkan beban listrik yang digunakan. Namun di setiap kondisi yang diterapkan nilai-nilai jitter yang didapatkan pada Pengujian ini masuk ke kategori baik sekali. 


\section{KESIMPULAN}

Berdasarkan pembahasan mengenai implementasi Komunikasi data menggunakan sistem PLC), maka dapat diperoleh berapa kesimpulan sebagai berikut.

1. Pada pengujian download dan upload, topologi jaringan dengan sistem PLC menghasilkan QoS yang lebih baik dibandingkan tanpa sistem PLC. Sedangkan pada percobaan streaming video untuk topologi jaringan tanpa sistem PLC menghasilkan QoS yang lebih baik dibandingkan dengan sistem PLC.

2. Pada pengujian dengan variabel jarak, delay dan jitter yang meningkat pada setiap penambahan jarak untuk percobaan upload. Sedangkan nilai yang dihasilkan throughput dan packet loss pada percobaan download, upload dan streaming video serta delay dan jitter pada percobaan download dan streaming video pada setiap jarak menghasilkan nilai yang cenderung konstan.

3. Pada pengujian dengan variabel beban listrik, parameter throughput dan packet loss untuk kategori download, menghasilkan nilai yang cenderung meningkat. Sedangkan nilai delay dan jitter menurun. Akan tetapi untuk kategori streaming video, nilai jitter cenderung meningkat sedangkan untuk throughput, packet loss dan delay menghasilkan nilai cenderung konstan. Kemudian pada percobaan upload untuk nilai throughput, packet loss, delay, dan jitter menghasilkan nilai cenderung konstan.

\section{REFERENSI}

[1] G. Lukitasari, A. Haryadi, and R. H. Y. Perdana, "Implementasi Powerline Communication Untuk Monitoring Penggunaan Arus Di Politeknik Negeri Malang," Implementasi Power Line Commun. UNTUK Monit. Pengguna. ARUS DI Politek. Negeri Malang, vol. VII, no. 2, pp. 74-78, 2018.

[2] [2] A. Rochadi, "Penggunaan Homeplug Av Powerline Adapter," Orbith, vol. 12, no. 1, pp. 1-10, 2016.

[3] [3] A. S. Pramudyo, Faris, and Suhendar, "Penerapan Power Line Communication Pada Sistem Monitoring, Controlling And Data Communication Melalui Sistem Kelistrikan 220 Volt AC," in Banten Teknik Elektro, Universitas Sultan Agung Tirtayasa, 2015, no. July.

[4] [4] M. K. Varma, Z. A. Jaffery, and Ibraheem, "Broadband power line communication: The channel and noise analysis for a power line network," Int. J. Comput. Networks Commun., vol. 11, no. 1, pp. 85-92, 2019 .

[5] [5] W. Sugeng, Instalasi Wireless LAN. Bandung: Informatika Bandung, 2005

[6] [6] A. W. Azinar, D. K. Hudalloh, and T. Informatika, "Analisis Quality Of Service Video Streaming Pada Ethernet Over Internet Protocol Dengan Metode Priority Queueing Dan Per Connection Queue," Integer J., vol. Volume 1, pp. 1-8, 2016.

[7] [7] R. Wulandari, "Analisis QoS (Quality Of Service) Pada Jaringan Internet (Studi Kasus: Upt Loka Uji Teknik Penambangan Jampang Kulon - LIPI)," J. Tek. Inform. dan Sist. Inf., vol. 2, no. 2, pp. 162-172, 2016.

[8] [8] Qualcomm.com, “AR7420 Chipset," Qualcomm Inc, 2014 [Online]. Available: https://www.qualcomm.com/products/ar7420 [Accessed: 03-Nov-2019].

[9] [9] R. Towidjojo, Mikrotik Kungfu Kitab 1. Yogyakarta: Jasakom, 2013.

[10] [10] Mikrotik.ID, "Data Over Powerline PL7400.” [Online]. Available: https://mikrotik.id/artikel_lihat.php?id=341. [Accessed: 12-Dec-2019].
[11] [11]European Telecommunications Standards Institute 2000 "TIPHON; Design Guide; Part 7: Design Guide for Elements of a TIPHON connection from an end-to-end speech transmission performance point of view," Etsi $\operatorname{Tr} 101329-7$, vol. V1.1.1, pp. 1-41, 2000 